\title{
Calibration of a building energy model using operation conditions derived from monitoring
}

\author{
Cristina Tanasa ${ }^{1, *}$, Cristina Becchio $^{2}$, Stefano Paolo Corgnati ${ }^{2}$, Valeriu Stoian ${ }^{1}$, and Daniel Dan $^{1}$ \\ ${ }^{1}$ Department of Civil Engineering and Building Services, Politehnica University Timisoara, 300223 Timisoara, Romania \\ ${ }^{2}$ DENERG, Politecnico di Torino, Corso Duca degli Abruzzi 24, 10129 Torino, Italy
}

\begin{abstract}
Building energy modelling and simulations play an important role in the design of energy efficient buildings but also in post-construction phases for commissioning, operation and optimization. With the use of data from monitoring systems related to the operation conditions of a building, calibrated simulations can be performed that accurately follow the real energy performance of a building. This paper present a procedure to achieve a calibrated building energy model simulation using monitoring data. The aim of the study is to verify/validate the results of the building energy model simulation against measured data. The study is based on an existing highly energy efficient building, which is continuously monitored in terms of energy consumptions and environmental parameters for several years now. The performance of the building energy model was assessed using statistical indices. The monthly total energy consumption comparison between simulated and measured shows that the building energy model managed to predict very closely the measured values. The accuracy of the building energy model in predicting air temperature was assessed as well.
\end{abstract}

\section{Introduction}

Building energy modelling (BEM) is an important process towards the design and optimization of buildings energy performance. The complexity of a building when it comes to creating a building energy model comes from the multitude of parameters including material properties, infiltration, uncontrolled ventilation, HVAC specifications and operation, occupancy schedules, temperature set points, equipment and lighting schedules, weather etc. All these parameters are vast sources of uncertainty in building modelling [1], which can be responsible for gaps between the simulated and real energy performance of a building and makes necessary the process of calibration. In a study made by Wang et al. [2], the authors investigate the uncertainties in energy consumption of a building due to actual weather and building operation schedules on the energy consumption of medium size office buildings. On one hand, the results show that the influence of yearly weather fluctuations has a relatively small impact on the energy consumption, ranging $-4 \%$ to $6 \%$ changes for different scenarios. On the other hand, changes in the building operation parameters have a greater impact on the energy consumption, uncertainties ranging from $-27.7 \%$ to $79.2 \%$. Martinaitis et al. [3] studied the influence of occupants' behaviour on the energy demand of an energy efficient house. They concluded that the use of different occupancy profiles results in changes on the total building energy consumption and thus, the use of actual occupancy information in building simulation improves the accuracy of the results. The interest in building energy modelling in post-construction phases has gained much interest in the past years and is frequently used to optimize the building operation and for savings determination [4]. The amount of data necessary for creating an energy model for an existing building is quite high and providing it with a high level of accuracy is the key in achieving a reliable and calibrated simulation. The Measurements and Verification Guidelines [5] presents the categories of data that are typically required in post-construction building energy simulation: utility bill records or energy consumption measurements, as built architectural drawings, comprehensive equipment and system data and weather data. The calibration process is a fundamental phase of the building modelling. It represents the process of adjusting the various input parameters in a model in order to achieve predictions of energy use that closely match the measured energy use of a building [6], [7]. Coakley et al. [1] made a review of existing methods for correlating building energy simulation results to real metered data. The review presents the current approaches related to model development and calibration. According to their research there is no explicit standard for calibration criteria and the existing guides only provide acceptable error ranges. Raftery e al. [8] presents a methodology for calibrating a whole building energy model to hourly energy consumption data, using measured lighting and plug load data in the simulation at

\footnotetext{
* Corresponding author: cristina.tanasa@student.upt.ro
} 
hourly intervals. The results prove the effectiveness of the method, the simulated energy consumption being close to the measured energy consumption. However, the authors acknowledge that the calibration of a building energy model to a high level of detail takes significant time and resources. Kim et al. [12] developed a method for building energy models calibration by using operation schedules derived from measured electrical energy consumption data. The results show a significant improvement on the accuracy of the building energy model simulations. Paliouras et al. [9] performed the calibration of a building energy model using measured indoor environment data for temperature, relative humidity and carbon dioxide concentration. The model was considered calibrated after 10 iterations and refining the input data of the ventilation system, window opening and solar shading devices. According to Royapoor et al. [10], the accuracy of building energy models can be improved nowadays due to the accessible monitoring equipment. In their research paper [10], Royapoor et al. examine the precision of a building energy model by using calibrated environmental sensors and a weather station. In this situation, the energy model of the building predicted the hourly air temperature in a year with a precision of $\pm 1.5^{\circ} \mathrm{C}$ for $99.5 \%$ of the time and $\pm 1^{\circ} \mathrm{C}$ for $93.2 \%$ of the time. One of the main benefits of having building monitoring data related to the energy consumption, environmental parameters and equipment parameters, consists in the fact that it offers precise input data to develop an accurate energy calculation model that can be further calibrated and validated. This paper follows the development of a building energy model towards a calibrated simulation for an existing residential building for which monitoring data is available.

\section{Methodology}

Although the calibration of building energy models is a topic of great interest amongst researchers in the field of building energy performance [8-10], currently there is no common and certified guideline and methodology for this process [11]. Therefore, calibrating a building energy model is a process that mostly depends on the modeller's knowledge and experience [11]. The methodology for building energy model calibration and simulation used in this research is based on a detailed literature review on the most recent methods used in the calibration of building energy models, as presented in the previous section. Figure 1 presents the main phases of the building energy model calibration and simulation procedure, which is a more accurate version of a procedure previously applied by the authors using a different set of data [15]. The methodology encompasses the analysis of the building energy model using as-built building physical parameters and systems, measured interior temperature, electricity consumption and weather data [19]. For this purpose, several steps are taken, as presented in Figure 1. When the building energy model is complete and has all the information, the first simulation is ran. An error verification is carried out in order to validate the results of the simulation, in terms of normalized mean bias error (NMBE) and coefficient of variation of the root mean square error (CVRMSE). The monitoring data is used firstly for creating the building operation pattern and further the monthly measured energy consumption will be compared to simulated energy consumption in order to assess the performance of the building energy model. The steps of the methodology are presented in detail in the following paragraphs.

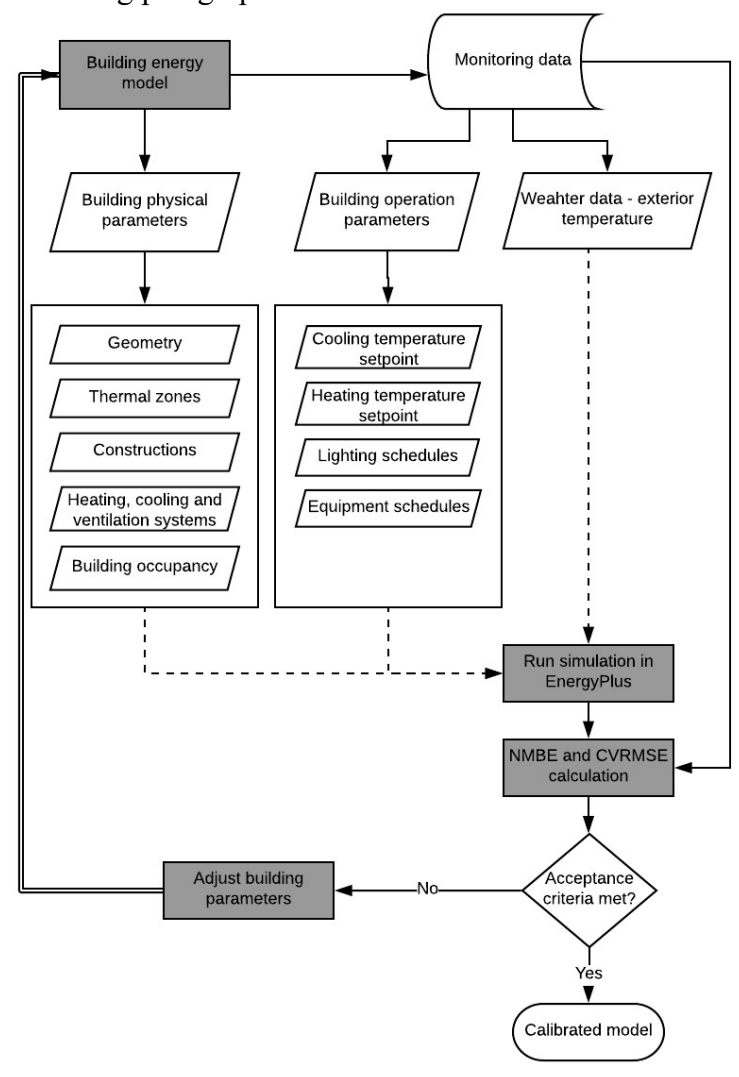

Fig. 1. Building energy modelling and calibration procedure.

\subsection{Building energy modelling}

The first phase of the methodology consists in defining the building physical parameters and characteristics by using as-built drawings of the building and construction materials. Also, the building systems features were defined based on the technical sheets provided by the manufacturers of the equipment. Once the building geometry and systems are accurately defined, the building operation parameters and weather data are defined. The modelling was performed using the EnergyPlus simulation tool. EnergyPlus is a dynamic energy simulation software that is used to model energy consumption in buildings (heating, cooling, ventilation, lighting, hot water use) and process loads, on an hourly basis. It is a simulation engine that can be used coupled with friendly graphical interfaces but can also be run stand-alone without such an interface. Energy Plus is characterized by flexibility and is not limited to predefined system configurations. The software has templates to be used for standard system structures that can be adapted for each situation in order to match the real building system that has to be simulated. For the 
simulations performed in this thesis EnergyPlus version V8.5.0. The building geometry was defined using coordinates and GoogleSketchup was solely used to verify the correctness of the geometry.

\subsection{Calibration procedure}

This phase implies the use of one full year monitoring data (2015). Thus, based on measurements, schedules were created for heating and cooling temperature set points and, hourly lighting and electric equipment energy consumption for internal loads. A custom weather data file is generated using hourly measured values for the exterior temperature, air relative humidity and wind speed. Also, the hourly measured temperature of the air after passing through the earth to air heat exchanger was defined as air node for the mechanical ventilation system. When the building energy model is complete and has all the information, the simulation is ran. A building energy model is considered calibrated when the differences between simulated and measured are within the accepted calibration tolerances. Currently, the validation of a building energy simulation model is based on standardized statistical indices that represent the performance of a model [13], [1]. The Coefficient of Variation of the Root Mean Square Error (CVRMSE) and the Normalized Mean Bias Error (NMBE) are the calibration metrics and are defined by equations 1 and 2 [12]:

$$
\begin{gathered}
N M B E=\frac{\sum_{i=1}^{n}\left(y_{i}-\tilde{y}_{i}\right)}{n \times \bar{y}} \times 100 \\
C V R S M E=100 \times \frac{\sqrt{\frac{1}{n} \sum_{i=1}^{n}\left(y_{i}-\tilde{y}_{i}\right)^{2}}}{\bar{y}}
\end{gathered}
$$

In equations 1 and 2 the following parameters were used: $\mathrm{n}$ is the number of measured data points; $\tilde{y}_{\mathrm{i}}$ is the simulated result at time $i ; y_{i}$ is the measured data at time $\mathrm{i} ; \bar{y}$ is the average value of $\mathrm{y}_{\mathrm{i}}$. ASHRAE Guideline 14 established criteria to be met by calibrated building energy models [13]. If the results of the simulation meet the acceptance criteria, then the building energy model is considered calibrated. If the calibration acceptance criteria is not met, further improvements and adjustments of the building energy model are required.

\section{Case study building}

The case study house is part of a duplex building, has two floors and approximately $141 \mathrm{~m}^{2}$ of living space. The building is located near the city of Timisoara, west side of Romania. The house was designed in accordance with the passive house guidelines. The building is southwest oriented, has a compact and regular shape, which comes from the intention of limiting the thermal bridges and heat transfer through the building envelope. The opaque envelope elements are highly insulated with polystyrene plates and mineral wool, having U-values below 0.15 $\mathrm{W} /\left(\mathrm{m}^{2} \mathrm{~K}\right)$. The windows are triple glazed and the window frames are insulated. The building is equipped with mechanical ventilation system with heat recovery, featured by an underground heat exchanger to preheat/precool the air. The heating and cooling are provided by an air to water heat pump and distributed through fan convectors installed in the ceiling. A solar collector is installed on the building roof to contribute to the domestic hot water needs.

\subsection{Monitoring data collection}

The building under investigation is equipped with a monitoring system. The design and implementation of the monitoring system were performed by the research team at the Politehnica University Timisoara. The design and implementation process are accurately presented in several scientific papers [14]. Figure 2 shows the schematic representation of the monitoring system implemented in the house.

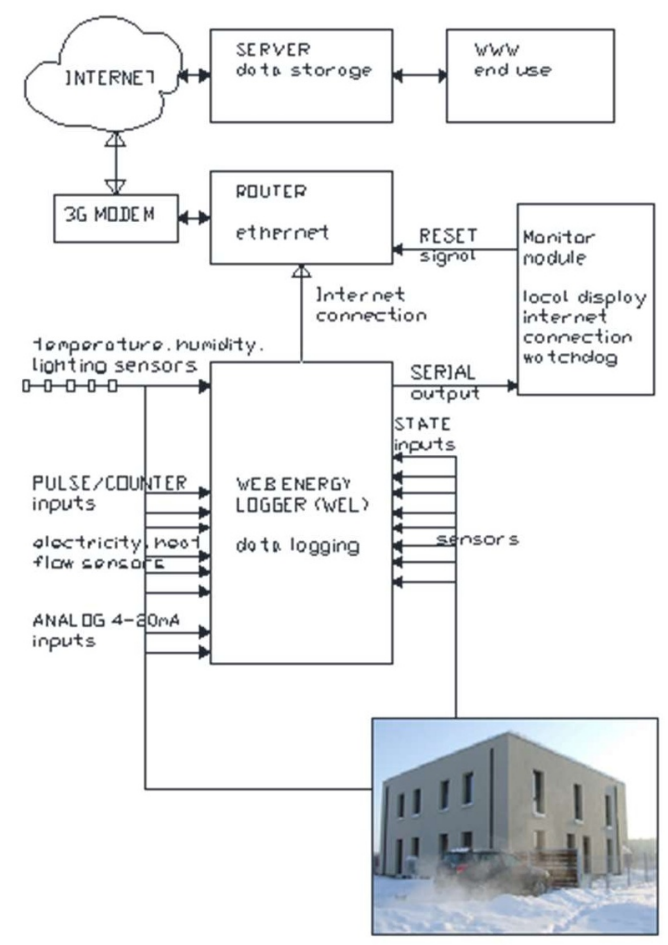

Fig. 2. Monitoring system scheme.

The monitoring system is composed of the central unit Web Energy Logger (WEL) and ambient energy flow meters. The system registers values at each minute and stores them on a server. The data files can be downloaded from the server as spreadsheets files for each month. Each monthly file contains approximately 44000 lines of values for each measuring component. The processing of the monitoring data was performed using Microsoft Excel tool. Based on one year monitoring campaign (2015), an accurate representations of the buildings' operation parameters and boundary conditions was developed. This was possible with information obtained from the building monitoring: data from energy meters and sensors, such as 
temperature, lighting and interior equipment electricity, outdoor climate data, which are implemented in the building energy model in the form of schedules and boundary conditions.

\section{The building energy model}

\subsection{Building parameters input}

The geometry of the building was created using as built drawings of the buildings and was directly defined in the EergyPlus IDF Editor by using coordinates and was exported in Google Sketchup for verification (Figure 3). The studied building is divided into two thermal zones The decision was made to separate the ground floor rooms from the first floor rooms, each of them being served by an individual fan system. As we can see in Figure 3, Zone 1 is composed of the ground floor spaces and Zone 2 consists in the first floor spaces. The two zones are part of the conditioned building area through heating and cooling thermostat set-points.

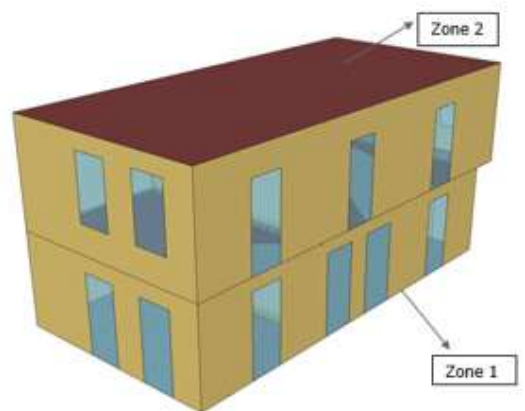

Fig. 3. View of the case study building geometry model.

Table 1 summarizes the building envelope characteristics, infiltration rate and mechanical ventilation air flow.

Table 1. Input data related to building envelope and ventilation

\begin{tabular}{|c|c|}
\hline Parameter & Input data \\
\hline $\begin{array}{l}\text { Envelope elements U-values } \\
{\left[\mathrm{W} / \mathrm{m}^{2} \mathrm{~K}\right]:}\end{array}$ & \\
\hline - External walls & 0.10 \\
\hline - Ground floor & 0.09 \\
\hline - Roof & 0.08 \\
\hline - Cantilevered floor & 0.07 \\
\hline - Windows & 0.90 \\
\hline Infiltration air change rate $\left[\mathrm{h}^{-1}\right]^{*}$ & 0.044 \\
\hline $\begin{array}{l}\text { Mechanical ventilation air flow } \\
\text { volume }\left[\mathrm{m}^{3} / \mathrm{h}\right]\end{array}$ & $100-250$ \\
\hline
\end{tabular}

The building systems were modelled considering the features and efficiencies specified in the technical books.
The air to water heat pump has a COP of 2.98, according to the technical sheet. The hot water storage buffer for heating has a volume of 5001 and a $3 \mathrm{~kW}$ electric heating element as a back-up source of heat. The domestic hot water is partially provided by a solar collector that has a surface area of $4.92 \mathrm{~m}^{2}$ and is placed on the roof. The domestic hot water is stored in a 150 litres boiler.

\section{Model calibration}

\subsection{Weather data}

Besides the data related to building operation condition, accurate weather data is necessary in order to match the building's response to external conditions from simulation with the real behaviour of the building. For this purpose, weather data registered by the monitoring system is available: exterior temperature (Figure 4), wind speed and air relative humidity. The custom weather file was created using Elements software tool [16] which is a free programme for creating and editing weather files for building energy modelling. The file was created from an existing weather file for Timisoara, downloaded from the EnergyPlus software web page in section Weather [17]. The weather file is freely available and is provided by ASHRAE IWEC2 (International Weather for Energy Calculations). In the existing weather file available for Timisoara, hourly measured air temperature, relative humidity and wind speed values were implemented and further used in the simulation.

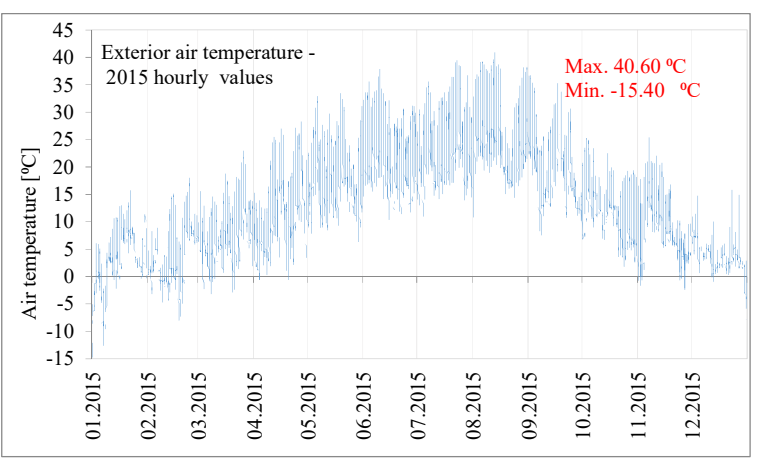

Fig. 4. Hourly measured outdoor air temperature.

\subsection{Indoor temperatures of unoccupied apartment}

The exterior walls, windows and roof are exposed to outdoors as boundary conditions and the ground floor is exposed to the ground. For the partition wall that separates the two apartments, the boundary conditions were defined in order to consider that in the other apartment of the duplex the temperature was lower because the space was not heated during the considered period of analysis, thus leading to thermal transfer between the two apartments. The outside boundary condition was defined in Energy Plus as 'OtherSideCoefficients' which has an associated object 'SurfaceProperty:OtherSideCoefficients'.

By referencing the 'OtherSideCoefficients' statement in the surface statements, the temperature of the outer plane 
of the surface is controlled through a temperature schedule. All heat transfer surfaces are simulated in the same manner through conduction transfer functions. The only difference between the various types of heat transfer surfaces is the environment on the other side of the surface [18]. Thus, a monthly average temperature schedule was defined based on the measured interior temperature in the unoccupied apartment of the duplex and assigned as boundary condition for the partition wall. The monthly average values of the measured indoor temperature of the unoccupied apartment are presented in Table 2.

Table 2. Monthly average temperatures - boundary conditions for partition wall

\begin{tabular}{|c|c|}
\hline Month & Monthly average temperature $\left[{ }^{\circ} \mathrm{C}\right]$ \\
\hline January & 20.89 \\
\hline February & 19.07 \\
\hline March & 21.99 \\
\hline April & 23.39 \\
\hline May & 24.94 \\
\hline June & 25.46 \\
\hline July & 28.22 \\
\hline August & 27.62 \\
\hline September & 25.94 \\
\hline October & 23.41 \\
\hline November & 18.74 \\
\hline December & 18.35 \\
\hline
\end{tabular}

\subsection{Mechanical ventilation air nodes}

The ventilation system is featured by underground heat exchanger to preheat and precool the air before entering the mechanical ventilation unit. The temperature of the air leaving the underground pipes was measured, thus being possible to use the hourly values as input data in the building energy model. The hourly measured values of the air temperature leaving the underground pipes are presented in the graph in Figure 5. These temperatures were introduced in the building energy model to serve as air intake for the mechanical ventilation system, replacing the outdoor air intake through a schedule file. In this sense, the 'EnergyManagementSystem' routines available in Energy Plus were used.

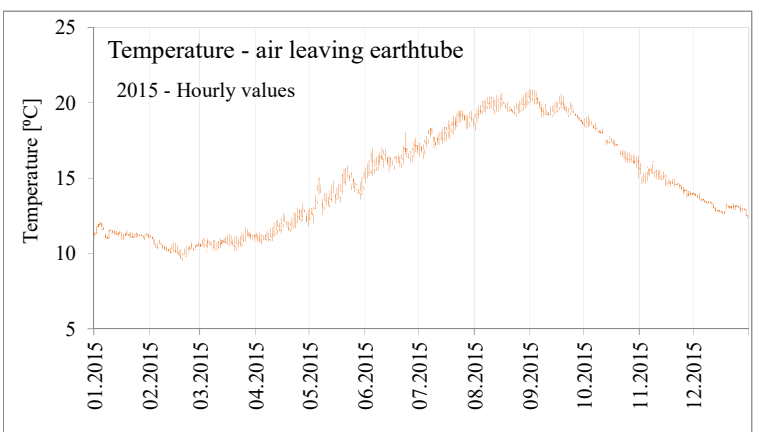

Fig. 5. Hourly measured air temperature after passing through underground heat exchanger - air nodes.

\subsection{Lighting and interior equipment}

A major part of the energy consumed by the interior electrical equipment and interior lighting in the building becomes a heat gain and influences the building energy balance. In order to define as accurate as possible the internal loads associated to interior lighting and electrical equipment, the electricity consumption periods were defined using schedules generated based on hourly monitoring data. For each month of the year, an hourly consumption weekday and weekend day profile was generated for interior equipment and lighting energy consumption, and the maximum hourly registered power consumption was determined for each category. The lighting and electrical equipment schedules were created as fractions of the maximum hourly registered power consumption in 2015: $3.96 \mathrm{~W} / \mathrm{m}^{2}$ for interior equipment and $1 \mathrm{~W} / \mathrm{m}^{2}$ for lighting. The graphs in Figure 6 and Figure 7 shows the hourly schedule for weekday and weekend day in case of a randomly chosen month.

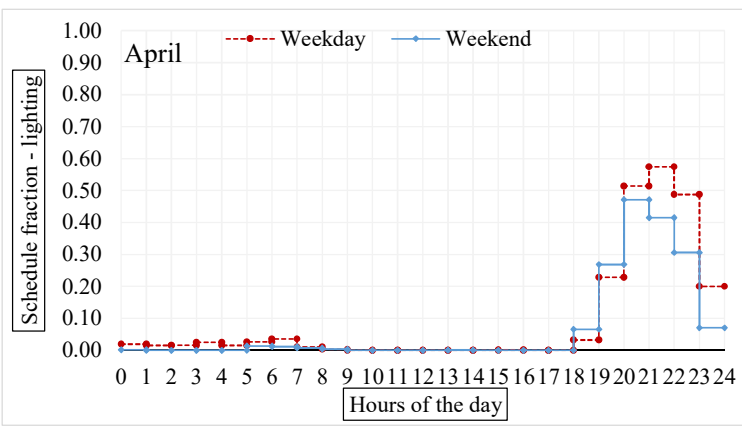

Fig. 6. Lighting schedules.

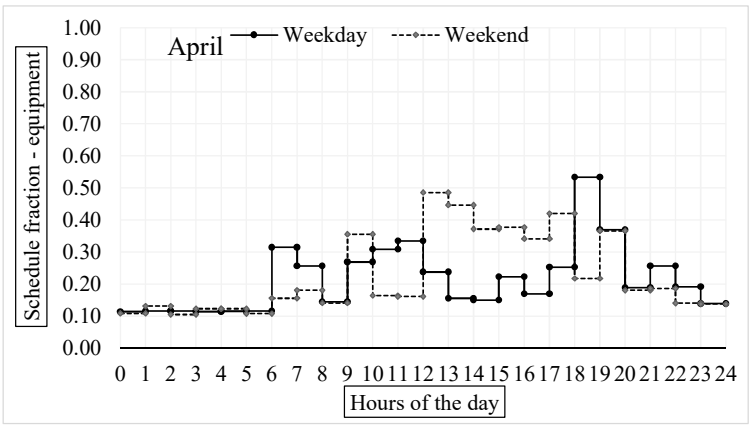

Fig. 7. Interior equipment schedules.

\subsection{Occupancy}

For the considered year (2015), the house was inhabited by a young family: two adults and one children The occupancy schedule was defined for weekdays and weekends, considering the information received from the occupants and is defined as fraction from the total number of occupants. Thus, a typical occupancy schedule was defined for weekday and weekend. During weekdays, between 22:00 and 07:00, the bedrooms are considered fully occupied (Zone 2), while the living room and kitchen (Zone 1) were occupied by two persons between 09:00 and 18:00 and fully occupied between 18:00 and 22:00. During weekends, Zone 2 considered occupied only between 23:00 and 10:00 and Zone 1 between 10:00 and 12:00 and between 15:00 and 23:00. 


\section{6 Heating and cooling temperature set-point}

The temperature control of the building is made through thermostat. An hourly day profile was created for each month when heating and cooling system were available (Figure 8). The heating and cooling set points schedules were defined using the measurements made on the interior temperature through monitoring. The heating system was scheduled to be available from the 15th of October until the 15th of April. According to the monitoring data, the cooling system was solely active in August.

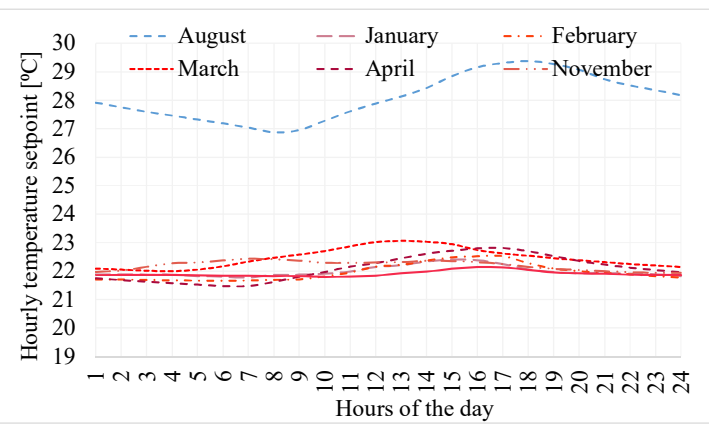

Fig. 8. Heating and cooling temperature set-points.

\section{Results discussion}

\subsection{Energy consumptions}

The total annual measured energy consumption of the building in 2015 was $5713.4 \mathrm{kWh}$ and the building energy model predicted a value of $5776.7 \mathrm{kWh}$, resulting that the simulation over-predicted the total energy consumption of the building with $1.11 \%$. A comparison between the monthly total measured and simulated energy consumption is presented in Figure 9.

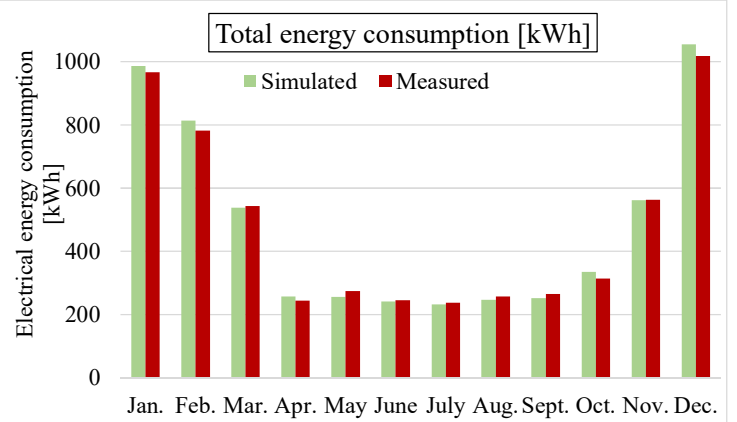

Fig. 9. Monthly total electricity consumption comparison: measured and simulated

The differences between the measured and simulated energy consumption are relatively small. Still, there is an amount of discrepancy left between measured and simulated values, especially in case of the energy consumption of HVAC system. The graph in figure 10 shows the monthly difference in energy consumption between the measured and simulated values. As said earlier, the differences related to energy consumption of the HVAC system are the highest and the ones related to lighting energy consumption are the lowest. It is noticeable that the simulation over-predicted more the energy consumption for the months when the house required heating. This fact indicates that the some uncertainties of the model are related to the heating system. The highest difference between measured and simulated is identified in December, when the simulation over-predicted the total energy consumption with 35 $\mathrm{kWh}$.

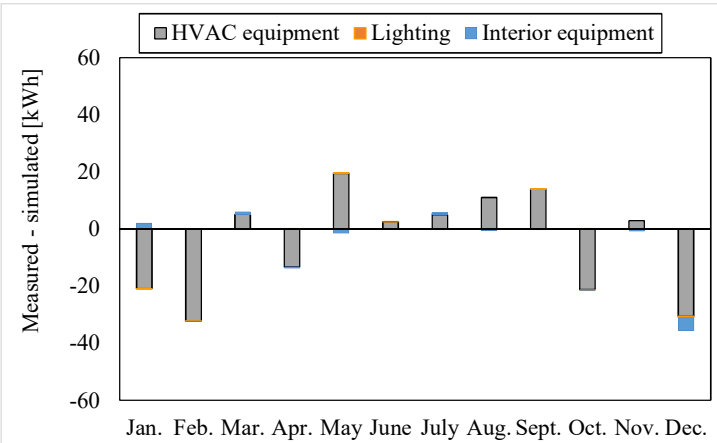

Fig. 10. Monthly total electricity consumption comparison: measured-simulated

The Normalized Mean Bias Error (NMBE) and Coefficient of Variation of Root Mean Square Error were calculated using Equations 1 and 2, on a monthly basis. The results presented in Table 3 show that the NMBE and CVRMSE values for monthly data are within the acceptance limit recommended by ASHRAE Guideline [13].

Table 3. NMBE and CVRMSE energy consumption values for the final building energy model

\begin{tabular}{|lll|}
\hline Category & NMBE* & CVRMSE** \\
\hline Total energy consumption & $-1.107 \%$ & $3.843 \%$ \\
\hline Heating, cooling, ventilation & $-1.376 \%$ & $5.054 \%$ \\
and domestic hot water & & \\
Lighting & $0.487 \%$ & $1.234 \%$ \\
Interior equipment & $-0.327 \%$ & $1.385 \%$ \\
\hline${ }^{*}$ NMBE acceptance limit $\leq \pm 5 \%[81]$ & \\
${ }^{*}$ CVRMSE acceptance limit $\leq+15 \%[81]$ &
\end{tabular}

\subsection{Indoor air temperature}

This section analyses the ability of the building energy model simulation to predict zone temperature. Figure 11 shows the NMBE and CVRMSE verification for temperature using hourly values, for each month and overall. The CVRMSE and NMBE values have the highest values in June and August, but they still they remain under the acceptance limit of 30\% (CVRMSE), respectively $\pm 10 \%$ (NMBE) for hourly values calibration [81]. Figure 12 shows the histogram of the residual values calculated by subtracting the simulated values from the measured values with Equation 3.

$$
\varepsilon_{i}=m_{i}-s_{i}
$$


The histogram shows the frequency of each residual value and the distribution and the centre of the histogram is somewhere around $0^{\circ} \mathrm{C}$.

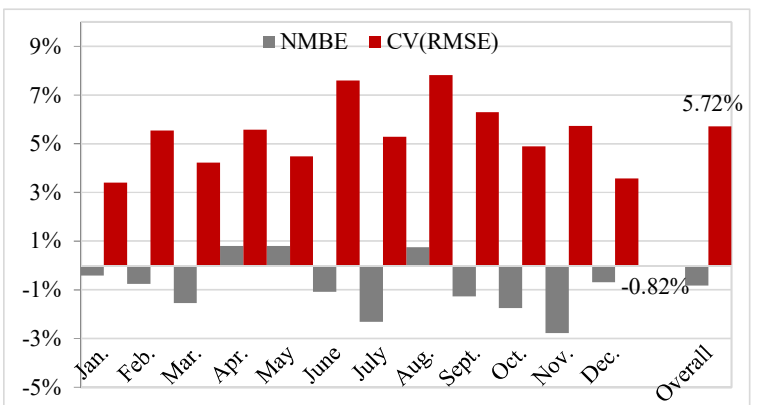

Fig. 11. NMBE and CVRMSE results for interior temperature (hourly basis).

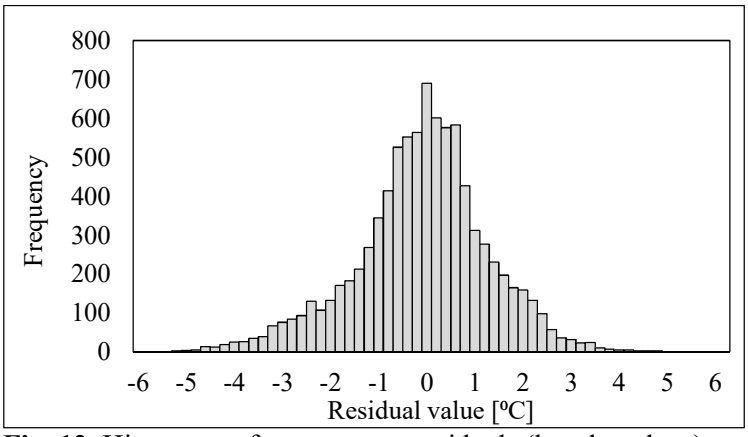

Fig. 12. Histogram of temperature residuals (hourly values).

The histogram has a normal distribution but with a slight asymmetry. We can observe a higher frequency of negative residuals which indicates that the simulation tends to over-predict the values of the air temperature slightly more often than under-predicts.Over the entire year, the measured indoor air temperatures are lower with and average value of $0.20^{\circ} \mathrm{C}$. The comparative analysis of measured temperature values against simulated ones indicate an overall good prediction of the building energy model. However, when it comes to comparing hourly measured values of space temperature with simulated values, the differences can be noticeable for some instances of time, because of a different distribution of real solar radiation than the one used in the simulation.

\subsection{Focus on the influence of heating temperature set point on the energy consumption}

Along with a calibrated building energy model, an analysis of the effect of different parameters variation on the energy consumption of the building can be investigated. For this case study, the impact of heating temperature set points on overall energy consumption is studied. The occupant behaviour feature that has a great influence on the energy consumption of the building is its perception related to indoor environment comfort temperature. Although the indoor comfort temperature is often a subjective matter, investigating its impact on the overall energy consumption might increase the user awareness towards a more effective use of the building. Using the calibrated building energy model, referred to as scenario S0, 4 other simulation scenarios were performed using lower and higher temperature set-points for heating. In the first two scenarios, S1 and S2, the heating temperature set-point of each month, used in the calibrated model (Figure 6), was reduced with $1^{\circ} \mathrm{C}$ and $2^{\circ} \mathrm{C}$. In the other two scenarios (S3 and S4), the heating temperature set-point was increased with $1^{\circ} \mathrm{C}$ and $2^{\circ} \mathrm{C}$. All the other input data of the building energy model remained unchanged.

The change in total energy consumption is highlighted in Figure 13.

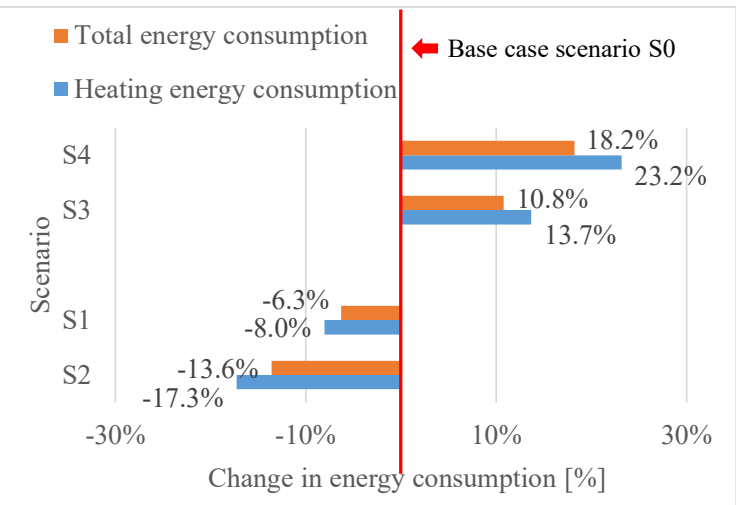

Fig. 13. Histogram of temperature residuals (hourly values).

A decrease of the heating temperature set-point with $1^{\circ} \mathrm{C}$, respectively $2^{\circ} \mathrm{C}$, leads to a decrease of the total energy consumption of $6.30 \%$, respectively $13.59 \%$. An increase of the heating temperature set point with $1^{\circ} \mathrm{C}$, respectively $2^{\circ} \mathrm{C}$, leads to an overall increase of the energy consumption of $10.77 \%$, respectively $18.24 \%$. The average heating set-point temperature for scenario $\mathrm{S} 1$ is approximately $21^{\circ} \mathrm{C}$, and leads to an $8 \%$ reduction of the annual heating energy consumption. In case of scenario $\mathrm{S} 2$, the average heating set point temperature is approximately $20^{\circ} \mathrm{C}$, and is the temperature usually used in the design phase of a residential building. For this case study, scenario S2 represents the most sustainable behaviour related to heating set-point temperature, resulting in a $17.3 \%$ reduction of the annual heating energy consumption.

\section{Conclusion}

The purpose of this research was to present the methodology applied for calibrating the building energy model for a residential case study. The development of a building energy model requires a great amount of information on one hand related to the building (geometry, envelope, systems) and one the other hand related to its operation parameters. Thus, in the simulation of a building energy model the uncertainty sources are multiple. In this research occupant behaviour related to the operation conditions of the building was defined using monitoring data for a year of occupancy. Weekdays and weekend days electricity profiles for lighting and interior equipment were created using hourly energy consumption measured data. The validation of the building energy 
model was performed using monthly energy consumption values and hourly interior temperature. The NMBE and CVRMSE values of $-1.11 \%$ and $3.84 \%$ for total energy consumption are within the acceptance limit of $\pm 5 \%$ and $15 \%$. The CVRMSE gives an overall evaluation of the difference between the measured and simulated values while the NMBE characterizes the bias of the difference. The comparison between simulated and measured energy consumptions shows that the building energy model simulation managed to predict very closely the measured values. The accuracy of the building energy model in predicting air temperature was assessed as well. The overall NMBE and CVRMSE values calculate for hourly instances of time are $-0.82 \%$, respectively $+5.72 \%$ and follow the calibration criteria to hourly values $( \pm 10 \%$, $30 \%$ ). Over the entire year, the measured indoor air temperatures are lower with and average value of $0.20^{\circ} \mathrm{C}$. The discrepancies between measured and simulated energy consumptions are within the acceptance limits and the building energy model is considered calibrated to monthly values. The remaining differences can be attributed in the first place to the lack of complete real weather data measurements. Although the weather file contains the measured exterior temperature, wind speed and air relative humidity, the measured solar radiation is missing.

The simulations investigating different heating temperature set-points shows that the heating energy consumption of the investigated building can be reduced with $8 \%$, respectively $17 \%$, if the heating temperature set point is reduced with $1{ }^{\circ} \mathrm{C}\left(\approx 21^{\circ} \mathrm{C}\right)$, respectively $2^{\circ} \mathrm{C}$ $\left(\approx 20^{\circ} \mathrm{C}\right)$. The results of this study emphasize the sensitivity of the overall energy consumption of a building to the heating temperature set-point. Therefore, in order to reduce the gap between the designed and real energy consumption of a building, several scenarios for temperature set point should be investigated in the design phase of a building. In this way, the awareness of the occupants on the energy saving potential related to their behaviour can increase and can also represent a strong motivation for them to adapt it accordingly.

\section{Acknowledgements}

This work was partially supported by a grant of the Romanian National Authority for Scientific Research,CNDI-UEFISCDI; project number PN-II-PT-PCCA-2011-3.2-1214-Contract $74 / 2012$.

\section{References}

1. D. Coakley, P. Raftery, M. Keane, Renew. Sust. Energ. Rev. 37, 123-141 (2014)

2. L. Wang, P. Mathew, X. Pang, Energ. Buildings 53, 152-158 (2012)

3. V. Martinaitis, E.K. Zavadskas, V. Motuziene, T. Vilutiene, Energ. Buildings 101, 64-75 (2015)

4. D.E. Claridge, Building Performance Simulation for Design and Operation 1, 13 (2011)

5. Federal Energy Management Program (FEMP), M\&V Guidelines: Measurement and Verification for
Federal Energy Projects Version 4.0; U.S. Department

6. Z.M.A. Chong, Bayesian Calibration of building energy models for large datasets (2017)

7. T.A. Reddy, ASHRAE Tran. 112, 226-240 (2006)

8. P. Raftery, M. Keane, A. Costa, Energ. Buildings 43, 3666-3679 (2011)

9. P. Paliouras, N. Matzaflaras, R.H. Peuhkuri, J. Kolarik, Energy Procedia - 6th International Building Physics Conference 78, 1227-1232 (2015)

10. M. Royapoor, T. Roskilly, Energ. Buildings 94, 109$120(2015)$

11. E. Fabrizio, V. Monetti, Energies 8, 2548-2574 (2015)

12. Y-S. Kim, M. Heidarinejad, M. Dalhausen J. Srebric, Appl. Energ. 190, 997-1007 (2017)

13. ASHRAE Guideline 14-2002: Measurement of Energy Demand and Savings; American Society of Heating, Refrigerating and Air-Conditioning Engineers: Atlanta, GA, USA

14. D. Stoian, V. Stoian, D. Dan, Buletinul AGIR 1, 150153 (2013)

15. C. Tanasa, V. Stoian, D. Stoian, D. Dan, Proceedings of The Sixth International Symposium on Life-Cycle Civil Engineering (to be published).

16. https://bigladdersoftware.com/projects/elements/

17. https://energyplus.net/weather

18. U.S. Department of Energy. EnergyPlus Version 8.5 Documentation. Input Output Reference.

19. C.M. Tanasa, Study on building energy efficiency using numerical simulations and in situ measurements, ISBN:978-606-35-0246-0 (2018) 